TE WHARE WĀNANGA O TE ŪPOKO O TE IKA A MĀUI

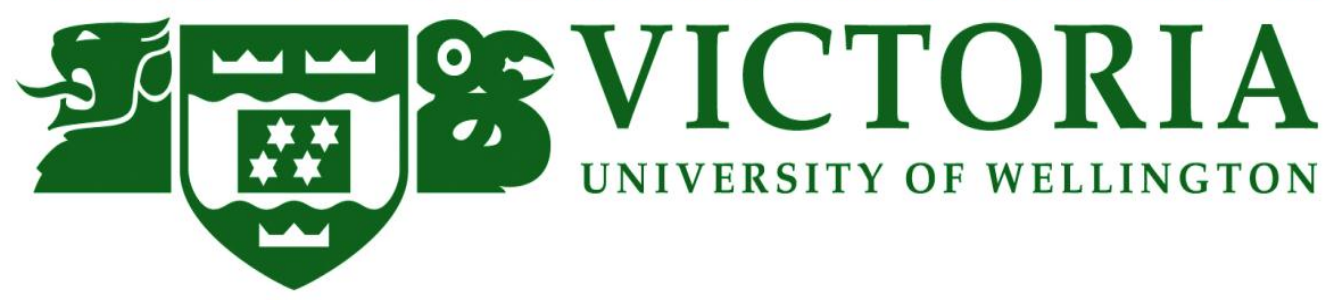

\title{
The Influence of Complexity in Determining New Product Development Strategies
}

A Study Examining the Development of New Software Products in New Zealand

MMIM592

by

Holger Spill

ID 300154689

Supervisor: Dr David Mason

Submitted to the School of Information Management,

Victoria University of Wellington

in partial fulfilment of the requirements for the degree of

Master of Information Management

18th October 2012 


\section{Preface}

This Report is not confidential.

I lovingly dedicate this thesis to my wife Kate, who supported me each step of the way on my MIM journey and proofread all my work.

Thanks to my supervisor, Dr David Mason, and the staff of the School of Information Management.

I also wish to thank those who agreed to be interviewed, for, without your time and cooperation, this project would not have been possible.

I certify that the Report is my own work and all references are accurately reported.

Holger Spill 


\begin{abstract}
How does complexity influence new product development (NPD) strategies? There are many ways of managing the challenge of new product development. This is especially true for new software products where a huge variety of approaches is possible. This study examines how successful New Zealand tech companies manage their NPD and how innovation complexity influences this. The new products are all software-intensive and have the additional pressure of being built for commercialisation.

The study found that while there is considerable variation within NPD, the level of innovation complexity determined the approach companies were taking. Companies with complex innovation challenges had more iterative software development; flexible internal processes; nimbleness in decision-making and re-prioritisation. Lower levels of complexity in innovation were linked to more formal and sequential approaches to NPD; less reviewing of process or product experimentation. Overall there were also lower levels of strain. The Cyclic Innovation Model (A. J. Berkhout, Hartmann, \& Trott, 2011) provides a useful description of how complexity in innovation is situated within a network of markets, customers, products and science and how innovation is not a linear, sequential process.

The study additionally suggests that strong entrepreneurial skills are essential to managing high complexity.
\end{abstract}

Keywords: innovation management, new product development, complexity, software, entrepreneurship 


\section{Table of Contents}

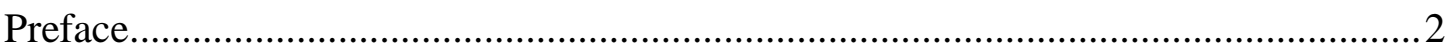

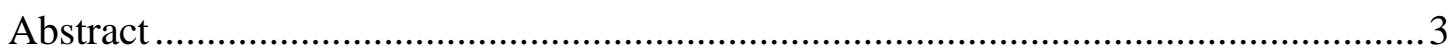

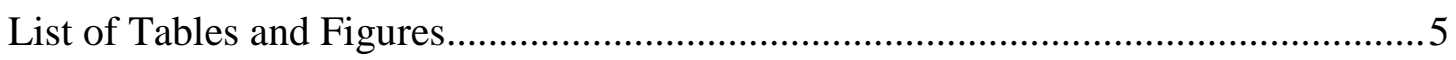

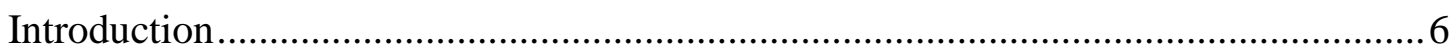

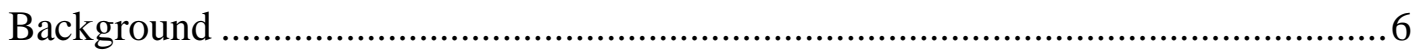

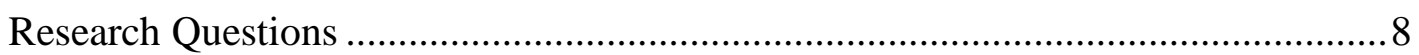

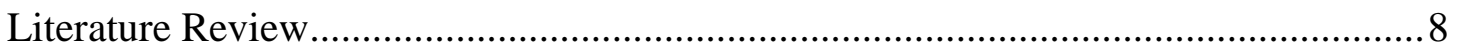

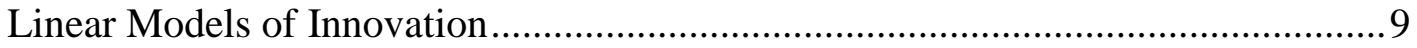

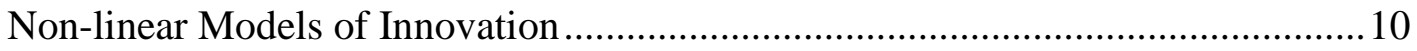

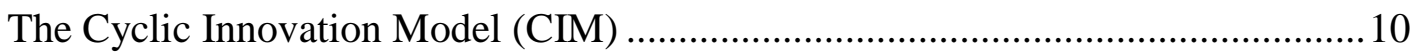

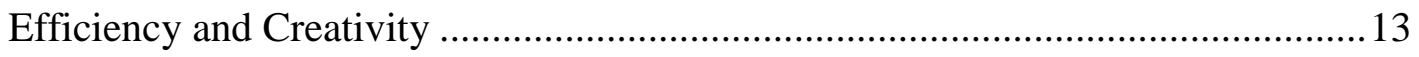

New Product Development with Software ......................................................... 13

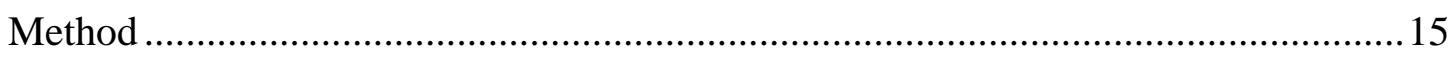

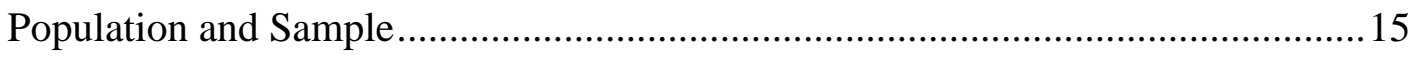

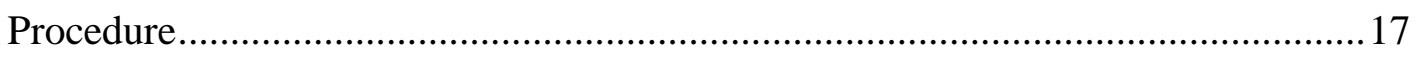

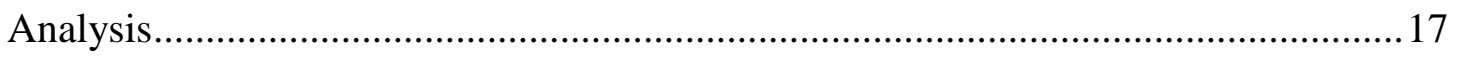

An Interpretative Approach to the Data Analysis ................................................ 17

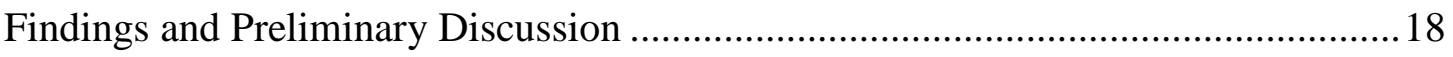

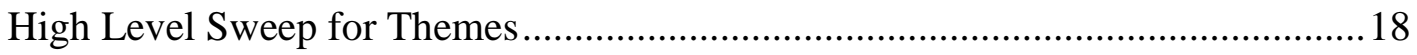

Back to the Literature and Refining the Research Question ......................................20

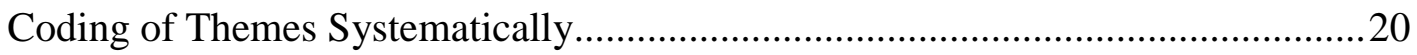

Level of innovation complexity - a new measure ............................................21

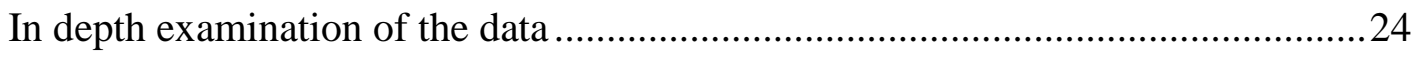

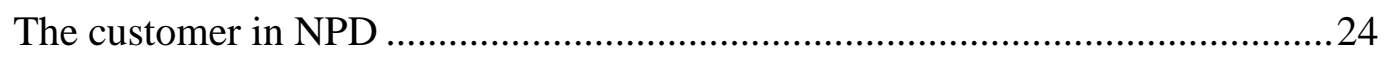

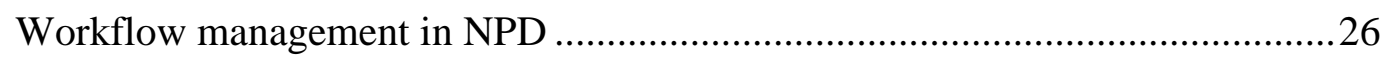

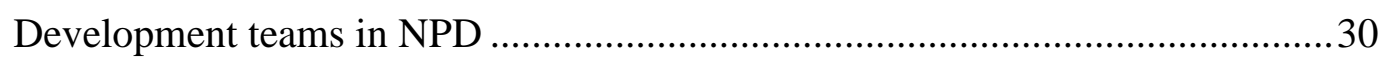


Managing the build in NPD .32

Innovation management from the founder perspective. .34

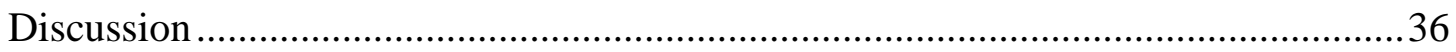

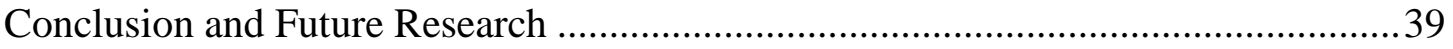

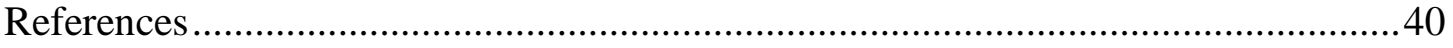

Appendix A - Interview Schedule ...................................................................... 44

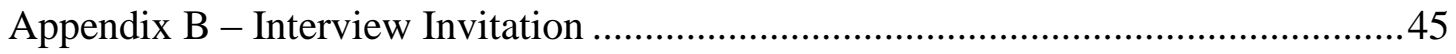

\section{List of Tables and Figures}

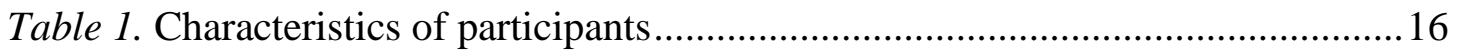

Table 2. Early themes occuring in the interviews...................................................... 19

Table 3. Companies rated on innovation complexity ...............................................22

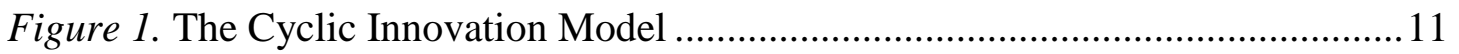

Figure 2. The modified CIM with a cloud computing example ................................ 12

Figure 3. Managing the tension between the need for creativity and efficiency......... 13 


\section{Introduction}

The purpose of this research is to investigate how New Zealand companies manage the development of innovative software products. Many factors come into play when new products are created and the literature on innovation management and new product development (NPD) is broad. Essentially, innovation management is about creating the conditions to enable a company to constantly adapt and be creative. NPD is more narrowly about the process of taking an idea, turning it into a tangible product and bringing it to market (Annacchino, 2003). The demands of both innovation management and NPD are high. They involve navigating complexity, taking risks within great uncertainty and making "thousands of decisions" (Pikkarainen, Codenie, Boucart, \& Heredia Alvaro, 2011, p. 108).

The population under study is New Zealand high tech companies who develop commercial software products. There are a large number of commercial pressures placed on the development process of these products. These pressures are not so evident in software products built to support the business process or those created via a voluntary participation process (e.g. Open Source Software). This adds a large amount of additional complexity to the development of innovative new software products.

Two strands come together to form the central points of this investigation. The first is the process of NPD with software products. This concerns itself with such things as the kind of software development methods; managing developer teams; and the role of experimentation during NPD. The second strand is the context of this NPD; specifically, the kinds of complex challenges which innovating companies face; how they deal with these; and what impact it has.

\section{Background}

Perhaps more than at any other time in New Zealand history, Government and policy makers are interested in how innovation works and how it can best be stimulated. There is a recognition that as the global economy changes, innovation will be a key component of the future wealth and prosperity of New Zealanders (Callaghan, 2009; Shanahan, 2011). In 2011 the Ministry of Science and Innovation was created and charged with the purpose of "leading the science and innovation ecosystem" (Ministry of Science + Innovation, 2011). In early 2012 it was further announced that this Ministry will be merged with the existing Ministry of 
Economic Development, underlining the expectation that science and innovation should be linked closely with business. New Zealand companies working in IT services and support and software development recorded a revenue growth of 13\% in the financial year 2010-2011, a considerable growth in revenue compared to the whole high tech sector (Shanahan, 2011).

One measure of a country's capacity for innovation is the Global Innovation Index (INSEAD, 2012). Seven areas are included in the measure: institutional environment, human capital and research, infrastructure, market sophistication, business sophistication, knowledge and technology outputs, and creative outputs. New Zealand's innovation ecosystem rates well overall in this index: in terms of its institutions (the regulatory and political environment in particular); creative outputs (e.g. recreation and culture consumption); market sophistication (e.g. ease of getting credit and of protecting of investors); human capital and research (e.g. investment in primary and secondary education).

The Global Innovation Index (INSEAD, 2012) shows that innovative ecosystems differ and that this has an impact on the level of business innovation in an economy. The majority of innovation management research originates in the United States, however, with its specific ecosystem factors, and usually concerns itself with large American companies (Dodgson, Gann, \& Salter, 2008). There is also a strong body of research emerging from Europe (Curzio \& Fortis, 2005). Scholars have noted that there are limitations on how much this research can be applied to other contexts (Pikkarainen et al., 2011; Sundbo, Gallina, Serin, \& Davis, 2006). Hence, local empirical studies of innovation management are valuable to furthering understanding of this field.

Getting the NPD right is a crucial aspect of innovation management and failures exemplify how critical this is. For instance, a recent local example is the online auction service wheedle.co.nz which has been taken offline due to unforeseen technical difficulties. This happened just a day after an expensive launch of the service across a variety of media; including television advertising. When technology commentator Ben Gracewood tweeted that users could set their own reserve on any Wheedle auction (essentially naming the minimum selling price of any product listed) the news spread quickly that Wheedle had been launched without sufficient quality assurance (Fletcher, 2012). The cost to Wheedle of this NPD failure is currently inestimable. Whether the site can regain customer confidence, especially against a long established competitor, is unclear. 
The Wheedle example illustrates how crucial and involved the management of NPD is. These failures are also not uncommon. Meeus (2006) notes that innovation has become a more extensive and complex activity than it was in the past. Speed to market, more interconnected technology, high consumer expectations and more complex problems to solve often make the NPD process more fallible.

\section{Research Questions}

This study will focus on the following research questions:

- What approaches to new product development do companies take when creating software products?

- How does complexity relate to the new product development approach?

\section{Literature Review}

The field of innovation management is broad and multidisciplinary (Trott, 2012). Despite being a focus of much research for decades, there is far from a consensus view on how innovation takes place (Sundbo et al., 2006). Moreover there is no strong agreement on foundational principles, although recently there have been synthesizing attempts from a variety of disciplinary viewpoints (Loch \& Kavadias, 2007; Pikkarainen et al., 2011; Smith, 2007). The focus here will be on reviewing selected literature from management studies.

Any discussion of innovation management must reference the early contribution of Schumpeter in his historically important work on capitalism and entrepreneurship which was originally published in the 1930s (Larson, 2000). According to Schumpeter, entrepreneurs are unlike traditional capitalists as they venture into new areas, creating opportunities and changing the market through their innovations. This creates a process of renewal; old world orders are taken apart while new ones come into being. This early focus on renewal, change, exploitation of opportunities and the understanding that at the heart of innovation is entrepreneurship has deeply influenced certain strands of innovation studies (Hagedoorn, 1996). It is a strongly interdependent view of innovation and the marketplace - both feed into each other. Carrying on in this tradition is Drucker's seminal work Innovation and Entrepreneurship (1985). Drucker's uncanny ability to succinctly summarize a problem is worth quoting at length: 
Innovation is the specific tool of entrepreneurs, the means by which they exploit change as an opportunity for a different business or a different service. It is capable as being presented as a discipline, capable of being learned, capable of being practised. Entrepreneurs need to search purposefully for the sources of innovation, the changes and their symptoms that indicate successful opportunities for innovation. And they need to know and apply the principles of successful innovation (Drucker, 1985, p. 17).

The fundamental point Drucker (2002) makes is that innovation is a systematic, entrepreneurial process which can be managed. In this way, innovation does not emerge fully from flashes of inspiration and inventiveness; rather it emerges through the role of the entrepreneur. Drucker (2002) puts the relationship thus: "The term [entrepreneurship] (...) refers to a certain kind of activity. At the heart of that activity is innovation: the effort to create purposeful, focused change in an enterprise's economic or social potential" (p. 96). In Drucker's view, innovation must be systematically and purposefully consolidated into a way of doing business so that new opportunities to find and serve customers are not missed. These activities will also involve systematic abandonment of parts of the business which do not perform as well, even if they represent the very products or services which have defined the business in the past (Stevenson \& Jarillo, 1990). It is worth noting also that this picture of innovation as a managed process is at odds with the view of innovation in the popular imagination where the inventive garage creator is celebrated. Individual inventiveness and creativity is only one aspect of the management of innovation (Derby, 2012).

\section{Linear Models of Innovation}

Linear models of innovation have dominated thinking for many decades (Sandberg, 2008). These models break the innovation process into a pathway, describing it in terms of a series of steps in NPD. From idea generation, to concept and development, testing and commercialisation, a product is developed (e.g. Barczak, Sultan, \& Hultink, 2007; Cooper, 2008; Sandberg, 2008). Often there is an implied stage-gate: when one activity ends, another begins. Berkhout, Hartmann and Trott (2010) group linear models of innovation into two variations: technology-driven models and customer-needs-driven models. Both share the weakness of focusing on the initial driver, the starting point for the innovation, rather than a whole dynamic model.

The usefulness of linear models of innovation is that they break the process down into steps which are explicable. They offer a blueprint for thinking about NPD, even if this 
blueprint has its limitations through its simplification. Scholars have argued that this is perhaps the primary reason for these linear models: they are less descriptive of actual innovation practice and more about providing a formalised guideline which creates project legitimacy and a gives a sense of order in a complex and sometimes chaotic process (Smith, 2007). Linear models of innovation have also strongly influenced thinking about software development methods.

\section{Non-linear Models of Innovation}

In contrast, Ven, Polley, Garud, and Venkataraman (1999) present the innovation process as simultaneously taking place along six dimensions which are best explained by: theories of change; organisational learning; leadership; new business start-ups; and relationships both inside and outside the organisation. Innovation management thus is presented as a broad group of activities set in nonlinear dynamic patterns. These activities are inhibited and facilitated by various factors inside and outside organisations.

It is not surprising given this explanation that knowledge management scholars have weighed in on innovation. Nonaka and Kenney (1991) state that innovation is an information process which ripples and flows resulting finally in an actual product. The process is not one of logical deduction, or sequential steps. Importantly the manager's role is similar to that of a knowledge manager: facilitating the flow of information - tacit, intuitive and explicit - by removing constraints inside and outside the organisation. Thus, the initial impulse for innovation can come from many places and can have many drivers. It does not necessarily follow a linear path and managing it always involves a series of interconnected activities.

\section{The Cyclic Innovation Model (CIM)}

The Cyclical Innovation Model (CIM) emphasises how innovation is a complex interwoven activity (Berkhout et al., 2010). The four poles of the Cyclic Innovation Model are product creation, market transitions, scientific exploration and technological research (see Figure 1). Essentially, these represent the four poles of industry (the supply), markets (the demand), basic science research and technology research. These poles interact in different ways. For instance, markets and industry together create customer value. While science and technology together create technical capabilities, technology and industry create technical functions. Together science and markets create what the authors call social insights 
(and, it is implied, social change). Entrepreneurial skills are needed to negotiate the challenges which are constantly arising from these poles.

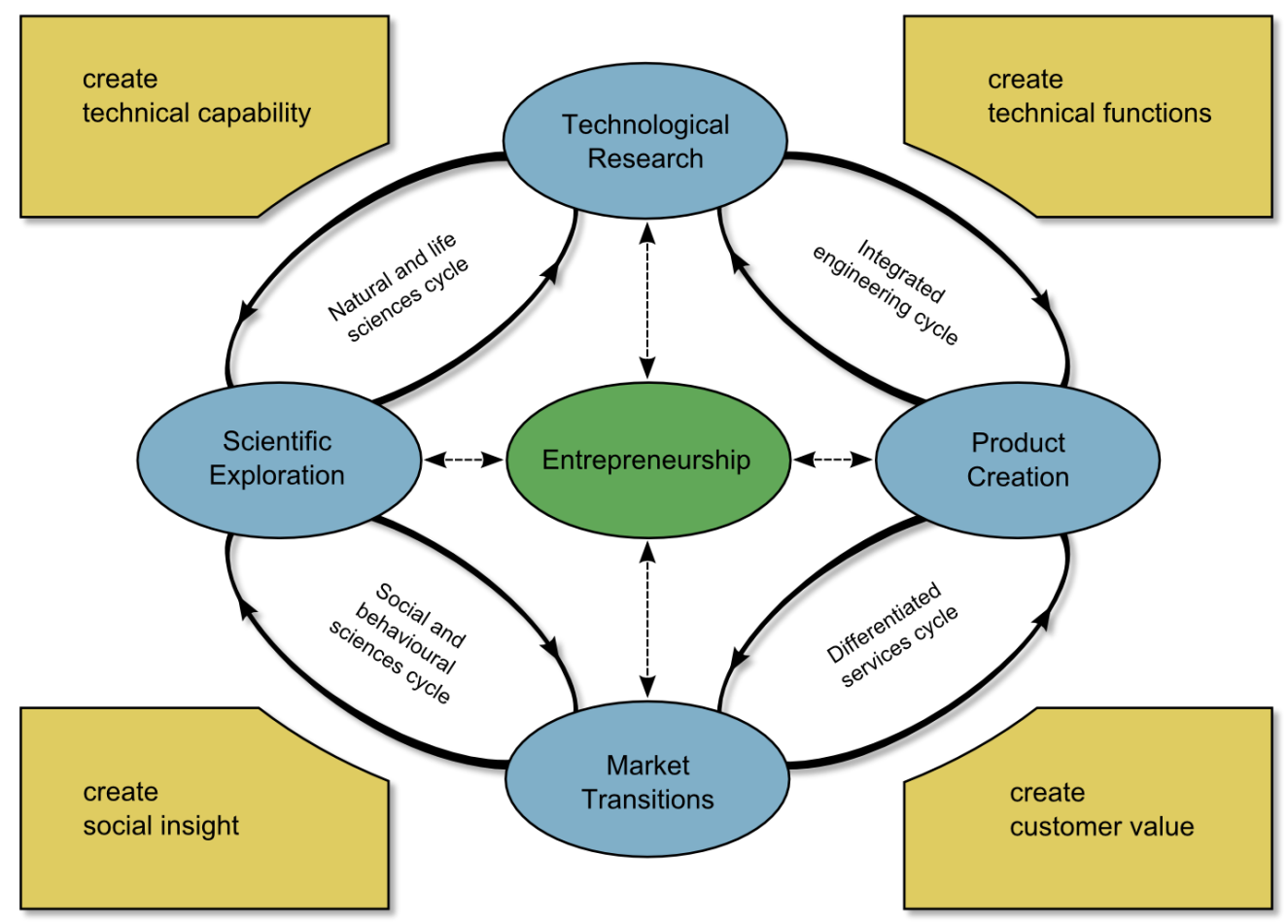

Figure 1. The Cyclic Innovation Model. Reprinted from " The role of entrepreneurship in innovation,” by A. J. Berkhout, D. Hartmann and P. Trott, 2011, International Journal of Entrepreneurship and Innovation Management, 14(1), fig. 3. Copyright by 2011 by Inderscience.

The CIM provides a useful way of thinking about complexity in innovation and emphasises that NPD is an interconnected, iterative process. For instance in the case of NPD of cloud services, the product is built on new software technology which in turn creates additional capability for new on-demand products using the cloud. The market informs which products are desirable and what role customization needs to play in this new product. In this way, products change the market and social behaviour which in turn is of great interest to social sciences which offer theories and insights into online behaviour, demographics and social changes. Scientific advances in data compression yield new capabilities for software in cloud computing. This example could equally apply for robotic automation, mobile applications or game consoles. The point is that there is a cycling between the technology and product poles representing engineering; between the product and the market poles, 
representing product customization. There is also cycling with the science pole which provides both behavioural and social science knowledge which can be applied to market/customer behaviour and physical and natural science knowledge which can be applied to technology. In this way, the CIM usefully demonstrates that the development of a new software product takes place within an environment of complex influences.

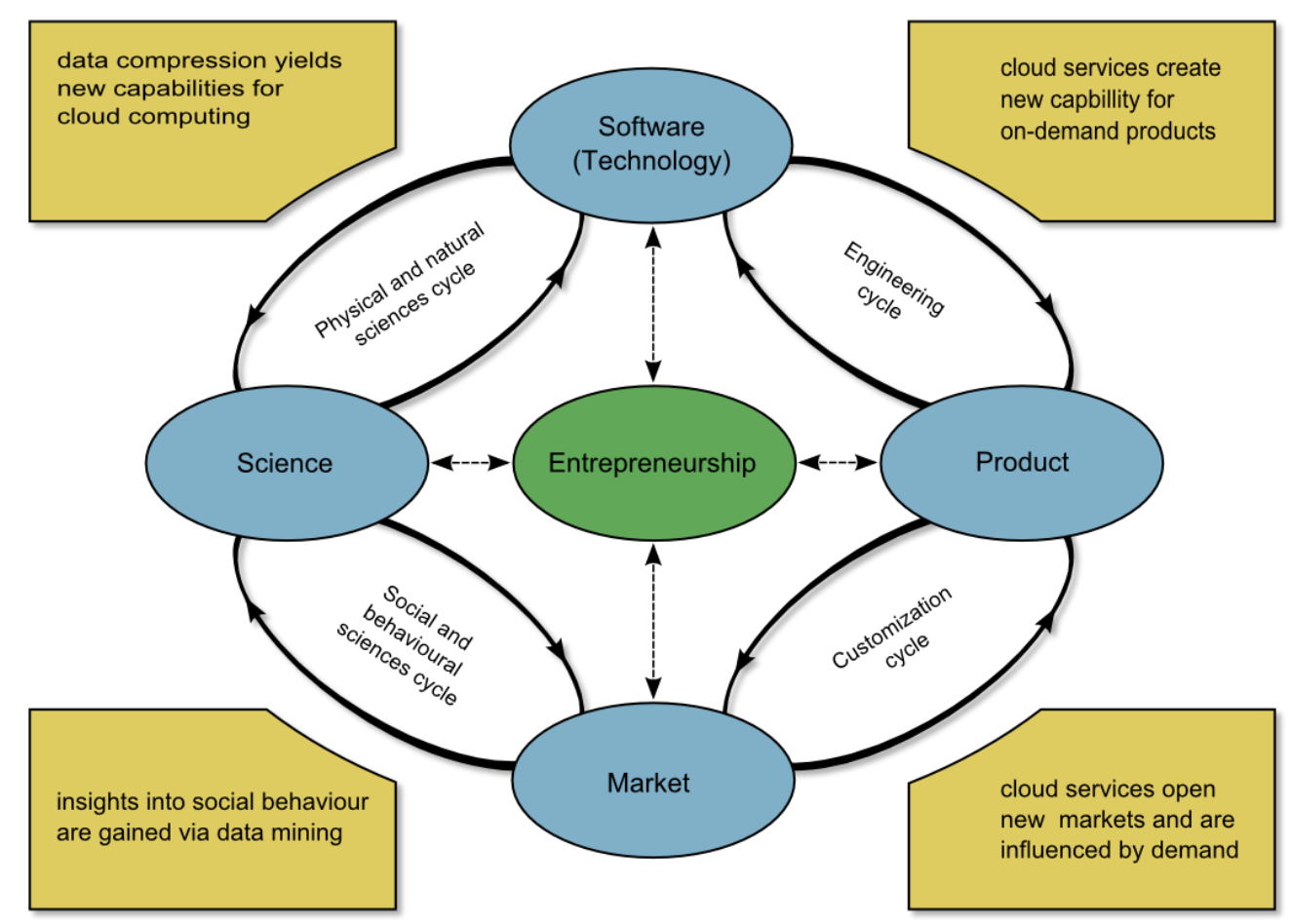

Figure 2. The modified CIM with a cloud computing example. Adapted from " The role of entrepreneurship in innovation,” by A. J. Berkhout, D. Hartmann and P. Trott, 2011, International Journal of Entrepreneurship and Innovation Management, 14(1), fig. 3. Copyright by 2011 by Inderscience.

Accordingly, innovation management and NPD demand entrepreneurship in order to turn the complexity of innovation into business value. By using the term entrepreneurship rather than management, Berkhout et al. (2010) draw attention to risk-taking, venturing, operating within uncertainty and outside standard process in a similar vein to Drucker and Schumpeter, as discussed earlier. The model emphasises complexity and does not represent innovation management as a series of steps in a chain, rather it is a cyclical, overlapping process. Hence, "causality is not a meaningful concept anymore" (Berkhout et al., 2010, p. 
485). New ideas may begin anywhere on the model and influences cycle in a spider web of different directions.

\section{Efficiency and Creativity}

Trott (2012) describes the dilemma of innovating companies as being a struggle between openness (which fosters creativity, new ideas and flexibility) and the drive towards optimising operations and creating stable repeatable processes (which create efficiencies). This tension is illustrated in Figure 3.

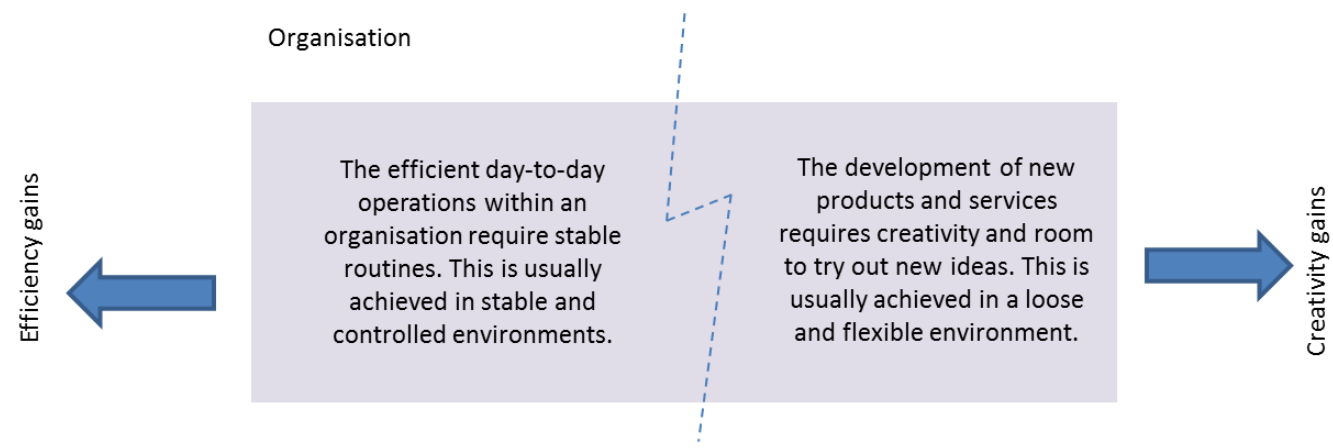

Figure 3. Managing the tension between the need for creativity and efficiency. Apdapted from "Innovation Management and New Product Development (5th ed.)" by P. Trott, 2012, fig. 3.1. Copyright 2012 by Prentice Hall/Financial Times.

Within competitive crowded markets, innovating companies need to successfully manage on the one hand squeezing out extra costs and inefficiencies while on the other cultivating a culture of work where people can experiment with new ideas. Trott (2012) describes this as simultaneously "reducing slack" and "allowing slack" (p. 84) in the system. O'Reilly and Tushman (2007) argue that successful companies manage the tension between innovation and efficiency by building "dynamic capabilities" (p. 6). There needs not be a trade-off in spite of the tension.

\section{New Product Development with Software}

Software products have distinctive NPD challenges and the models of NPD which apply to manufactured products do not easily fit software products. Pikkarainen et al. (2011) usefully outline five reasons why innovation with software is different. First, software is malleable. It is a product which can be endless changed via features, it can be delivered in 
small chunks and to some types of users first, and there are almost endless ways of achieving functional goals. This can be a benefit as well as a pitfall; as more choices require more prioritising and decision-making. Second, software is intangible. This makes it easily transportable but harder to conceptualise outside of its technical functionality and its User Interface (UI) design. It cannot be held in the hand and tried out. It must be experienced and played with. Third, the barriers to setting up business in the software market are relatively low. In contrast to manufacturing or any industry where networks or service is important, the upfront investment and cost of distribution can be low. This makes the software market more volatile: large and well-established companies can and often do compete against market newcomers. Fourth, consumers play a different role in software to other products. No-where is this clearer than in Open Source Software (OSS), where the user becomes co-creator. Many new business models take advantage of different kinds of software consumers: as power users, as community. Hence, ways of thinking about customers and their roles are different. Fifth, critical experts can have an outscale impact on product performance. Hence, the relative scarcity of excellent software engineers makes competition for these critical experts high. McConnell (2011) argues that the productivity of expert software engineers can be up to $10 \mathrm{x}$ greater than merely "good" software engineers in the right organisational setup.

So software with its distinctive characteristics demands its own kind of NPD approach. One such approach is iterative software development. Iterative software development dates back to the mid-1950s, although it is often considered to be relatively new (Larman, 2004, chap. 6). As a method for managing the software development process it has gained hugely in popularity and acceptance in recent times. Today agile is an umbrella term which brings together iterative and incremental software development methods. They may differ in details but have the common goal of avoiding the shortcomings of the sequential and document-driven waterfall process. Work is broken into cycles (iterations) and small deliverables are created which build on previous iterations. Feedback, review and adaptation play an important role in this process and influence further planning (Boehm, 2011). An exploratory phase determines the estimates needed to derive schedules. According to an agile software development philosophy, it is impossible to create unchanging and detailed specifications at the early stage of development.

In contrast, the waterfall method of software development puts great emphasis on upfront specifications and a document-driven process (Benediktsson, Dalcher, Reed, \& Woodman, 2003). It owes a lot to linear models of innovation in that it is sequential with 
distinct phases of development. Moving to the next phase is only possible when the previous phase is complete. Estimates are calculated upfront and the software development is seen as an execution of a design which is created early in the process. It is not easily possible to backtrack or modify design once that phase is complete. Waterfall is traditionally the way software has been managed since exploding in the 1970s (Larman, 2004). This method lends itself well to a formalised environment with stable requirements. Criticisms of this method include that it is too rigid, not customer-focused, and that it does not match the reality of a creative development process where change is part of building something new (Smith, 2007, chap. 1).

While these two methods have been presented as deeply contrasting, in reality there are many variations on them. Waterfall and agile are sometimes combined, for instance, where iterations take place within phases of a waterfall project. Further, McConnell (2004) argues that "an iterative approach that ignores prerequisites can end up costing significantly more than a sequential project that pays close attention to prerequisites" (p. 34).

\section{Method}

\section{Population and Sample}

The population under study is high tech companies whose primary revenues are from commercialised software products. A further criterion was that they must have a proven track record of NPD success (i.e. at least one product successfully brought to market) and be primarily based in New Zealand. Excluded from the population were related high tech fields such as telco solutions, electronics, pure IT services and support, and high tech businesses where software does not play a central part of the business offering (e.g. manufacturing).

To find a sampling frame from this population, a search was done via Government websites (Ministry of Science and Innovation, Ministry of Economic Development, New Zealand Trade and Enterprise), NZX Index and NZX SciTech Index, the TIN100 report, New Zealand High Tech Awards, the New Zealand Innovation Network, Trade publications (e.g. Computer World) as well as mainstream media (New Zealand Herald, Radio New Zealand archives).

As a result, 24 companies were invited to participate per email, telephone request or via a LinkedIn invitation (Appendix B, interview invitation). The names of the companies 
cannot be included due to confidentiality. The companies cover a spectrum of business maturity: start up, growth, established and expansion. Three of the companies are large (using the definition from Statistics New Zealand of 100+ Full Time Employees), and five are small-to-medium sized enterprises (SMEs).

\begin{tabular}{|c|c|c|c|c|c|c|}
\hline Participant & Interviewee & Size & Growth & Ownership & Customers $^{\dagger}$ & Product/s \\
\hline Digitaldeal & $\begin{array}{l}\text { Head of product } \\
\text { development }\end{array}$ & Large & Established & Listed & $\mathrm{C}, \mathrm{B}$ & Online trading \\
\hline Webfabrik & Founder & ME & Start up & Private & $\mathrm{B}, \mathrm{C}$ & $\begin{array}{l}\text { Tools for } \\
\text { manufacturing }\end{array}$ \\
\hline Cloudway & Founder, CTO & ME & Start up & Private & $\mathrm{B}, \mathrm{C}$ & $\begin{array}{l}\text { Middleware \& } \\
\text { cloud services }\end{array}$ \\
\hline Medimage & Founder & SME & Start up & Private & $\mathrm{B}, \mathrm{PS}$ & $\begin{array}{l}\text { Medical } \\
\text { imaging }\end{array}$ \\
\hline Cybersoft & $\begin{array}{l}\text { Head of product } \\
\text { development }\end{array}$ & Large & Established & Private & PS, B, C & $\begin{array}{l}\text { Financial crime } \\
\text { analysis }\end{array}$ \\
\hline Financialware & $\begin{array}{l}\text { Prod. development } \\
\text { manager }\end{array}$ & Large & Established & Private & $\mathrm{B}, \mathrm{C}, \mathrm{PS}$ & Financial tools \\
\hline Bizware & Founder & SME & Growth & Private & B & $\begin{array}{l}\text { Management } \\
\text { tools }\end{array}$ \\
\hline Infotree & Founder & SME & Start up & Private & $\mathrm{B}$ & $\begin{array}{l}\text { Business } \\
\text { software }\end{array}$ \\
\hline
\end{tabular}

Table 1. Characteristics of participants

From this sampling frame, eight companies agreed to be interviewed for the research. Table 1 shows an overview of the participant characteristics. There is an overrepresentation 
of Wellington-based companies in the sample. This might be due to an increased willingness to participate in a Victoria University of Wellington study.

All interviewees are senior product development managers, heads of development, Chief Technology Officers, or company founders close to the development process. The demographics of the interviewees are: all male, mid-career, and from a variety of professional backgrounds although mainly technical backgrounds. Many had international experience (such as working or training overseas). All companies in the sample have some business offering overseas. The main overseas markets where they are operating are: United States, Australia, United Kingdom, parts of Europe and parts of Asia.

\section{Procedure}

From exploratory readings of innovation management literature, the following themes were initially selected as the basis for the semi-structured interview questions: flexibility in the NPD process; prototyping and experimentation; uncertainty and risk management; people management; collaboration and co-creation; innovation ecosystem in New Zealand.

The interviews were semi-structured conversations either in person or via phone and were loosely structured according to the interview schedule (see appendix A for a sample of interview questions). Each interview lasted between 45-80 minutes. The questions relating to each theme were refined as the interviews went on and as the central role of complexity in innovation management emerged. The researcher asked a mixture of open and focussed questions supported by hypothetical examples to obtain a richer description. The participants were also encouraged to give examples from their experiences in NPD at their current companies.

The interviews were recorded and full written transcripts were subsequently made. The company names have been changed to pseudonyms to maintain anonymity.

\section{Analysis}

\section{An Interpretative Approach to the Data Analysis}

There are many approaches to the analysis of qualitative data (Punch, 2005). The key is that the data analysis method must be in keeping with the purpose of the study. The researcher must try to avoid information processing biases; such as making premature 
conclusions, being overly influenced by certain respondents (e.g. prestigious respondents), being influenced by data vividness, or "ignoring disconfirming evidence” (Eisenhardt, 1989, p. 540).

This study takes an interpretative approach to investigating the research questions. Interpretative research aims to understand phenomenon through the shared meanings which people assign to things, it concerns itself with both the context and the process of how phenomenon take place, and it does not set independent and dependent variables to be tested hence no hypothesis is created (Klein \& Myers, 1999). An interpretative approach is appropriate to this study for number of reasons:

- The purpose of the research is to gain understanding of how things work in NPD in software and what influences there are on the process.

- The interviews were semi-structured which means that no participant had exactly the same interview. Follow up questions allowed phenomenon described by the participants to be probed according to how the researcher was interpreting the participants' descriptions during the interview itself. The interpretative position encourages the researcher to make sense of the data as it is emerging and try to understand it from the participants' perspectives.

- Creating a hypothesis to be tested would limit the data analysis before it had even begun.

\section{Findings and Preliminary Discussion}

The following section will present in detail how the data were analysed. There were three principle stages of data analysis: (1) high level sweep for themes; (2) coding of themes systematically and in greater granularity; (3) in depth examination of the data.

\section{High Level Sweep for Themes}

Before each interview, publically available information about each company was collected (e.g. web presence, product range, main business activity, company history, business model). Rough notes were made during each interview and themes and questions which occurred after each interview were memoed. Full transcripts were made of each 
interview. This was time-consuming but useful to the interpretative approach as the data could be revisited more easily for patterns or understandings which were originally missed.

After all the interviews were complete the transcripts were scanned for commonly occurring words and themes. A further iteration of this was made after a time interval in an attempt to improve the reliability.

\section{Company Re-occurring themes}

Bizware

Governance, trust, customer, customer's customer, business value, local, "process of mutual discovery"

Webfabrik

Risk, emergent, "being the change you want to see", processes, change, product, delegation, challenge

Financialware Design, features, feedback, morale, team, opportunity vs priority

Cloudway Product evolution, idea evolution, early concept, customer value, make-iteasier, culture, local presence, go-to-market, challenge

Medimage Research, science, expertise, government grants, quality assurance, processes, regulation, liability

Cybersoft Prototype, expertise, $\mathrm{PhD}$, specialization, government grants, risk management, quality control

Digitaldeal Funnelling ideas, prioritising, roadmap, incremental deployment, features, fail fast, persona, attitude, Kiwi, improvement

Infotree Capital, adapting, business model, advisory board, changing approach, product uptake, sales conversion, users.

Table 2. Early themes occuring in the interviews. 


\section{Back to the Literature and Refining the Research Question}

A more extensive exploration of innovation management and NPD literature was made in light of these re-occurring themes. A number of themes were emerging which offered preliminary explanations to the research questions (especially around governance, complexity and how that related to innovation management). How these themes linked together was not clear. Seeing innovative product development as a series of linear steps seemed to overly simplify matters. Originally the research was aimed at understanding how experimentation and product incubation takes place in innovating companies but it became clear that a wider topic was more appropriate to the data. The research questions were refined in light of this to the current ones.

A number of participants implicitly or explicitly expressed the belief that in order to be innovative and customer-focused, only an agile method of software development could deliver the outcomes sought. Yet, two participants described software development method more in waterfall terms. This offered both an irritation and a source of opportunity.

An attempt was made to triangulate the data with a number of promising models from innovation management literature. In many, the level of analysis was not right (too high level or too granular - the nuts and bolts of NPD or software engineering). The Cyclic Innovation Model (Berkhout et al., 2010) with its emphasis on complexity was selected as offering a promising explanation of some of the emerging constructs.

\section{Coding of Themes Systematically}

In order to examine the themes which each participant describes in the data, reoccurring constructs were coded and put into a table according to the following categories. First, the kind of innovation complexity each company was facing in its NPD was coded as per the CIM (market, technology, product, science). For instance if the participant stressed working with researcher organisations in order to gather scientific information, then this theme "working with researchers" was added into the science category. If there were subthemes relating to this, then these were also noted. Second, themes which related to the category of working on the business (e.g. cashflow, business model development, raising venture capital, governance) were captured. Third, company maturity (start up, growth, established, expansion), size (large or SME) and participant role in the organisation (founder, technology product manager) were noted. 


\section{Level of innovation complexity - a new measure}

According to the CIM (Berkhout et al., 2010), innovation involves negotiating four poles of influence. These poles feed into each other and essentially represent challenges for the organisation to negotiate. To shorthand the level of challenge organisations encounter according to the CIM, Berkhout et al. (2010) refer to companies as a 2-level companywhere there are two levels of challenge on the CIM (e.g. product and science). A 3-level company has three challenges (e.g. technology, market and science).

Useful as this shorthand is, a greater level of detail around the level of challenge was sought. Describing a company as a 2-level company does not adequately describe the pressure of the innovation challenge. Hence, a measure was sought to gauge the level of challenge each company was currently experiencing on each CIM pole. The measure chosen is based on specific understanding of the notion of complexity as per the organisational theorist Elliot Jaques.

Jaques defined complexity in terms of time span (Brown, 2011); a complex task requires a long time span to be completed and will require many decisions along the way. Decision-making for complex tasks involves weighing up multiple factors and taking into account unknowns and contingencies. Knowing how to proceed requires many skills. For instance, long term strategic planning is a complex task. The outcome of decisions may take years to become clear. Predicting the future is complex and the decisions around a business model will take time to yield results in the market. Decisions around which scientific research to pursue may take a long period to yield results which can be applied to the product. Creating a complex piece of software, perhaps one which will need to be patented, will take time to plan, develop and make the "thousands of decisions" (Pikkarainen et al., 2011, p. 108) until it yields results. Less complex tasks are shorter, require fewer decisions and hence are less ambiguous. They are less challenging.

Accordingly, each company was rated in terms of its current level of complexity for the four CIM poles product creation, market transitions, scientific exploration and technological research. Ratings of low, medium and high complexity were given. The rating represents a snapshot in time for the company. These ratings would be expected to change over time as markets, products, science and technology all change. The coded data was referred to as a cross reference in this exercise. 


\begin{tabular}{|l|l|l|l|l|}
\hline Company & Technology & Science & Product & Market \\
\hline Bizware & Med & Low & Med & High \\
\hline Webfabrik & Med & Med & High & High \\
\hline Financialware & Med & Low & High & Med \\
\hline Cloudway & High & Low & High & High \\
\hline Medimage & Med & High & Med & Low \\
\hline Cybersoft & Med & High & Med & Low \\
\hline Digitaldeal & Med & Low & High & Med \\
\hline Infotree & Low & Low & High & High \\
\hline
\end{tabular}

Table 3. Companies rated low, medium, high innovation complexity according to product, market, science and technology.

To examine where the most extreme ratings were, the medium rating was ignored; instead the ratings of low and high were examined.

Technology - all companies in the sample except one score medium or high in terms of technology complexity. One company (Cloudway) stood out as currently having more complexity than the others and so rated high. This company is also at the leading edge globally in terms of its patented technology. One company scored low on technology complexity as much of the software is comprised of off-the-shelf components (Infotree).

Science - two companies (Cybersoft and Medimage) stood out as having high complexity ratings in terms of science. Both companies have products which are commercialised spin offs of world-leading scientific research. The science is highly specialised. Ensuring that they have the science correct and staying abreast of any developments in the science is a focus for both. 
Product - half of the companies scored high complexity in terms of their product creation. This was reflected in much concern by interviewees in differentiating and constantly improving their products

Market - four of the nine companies scored high levels of complexity in terms of their markets. All four reported dynamic and fast-paced markets. These four companies were all creating or proving their markets and optimising their strategy. There was a lack of clarity around what was going to happen next. Two companies scored low on the complexity of their current markets. This was because they had secured markets and customers for their current major products. They had market pull for their products and were outpacing their competition.

\section{Pairing cases}

The previous two exercises in data analysis had been revealing of the innovation complexity the companies were experiencing as per the CIM. Table 3 shows there are marked differences in companies across this measure.

Eisenhardt (Eisenhardt, 1989) describes the method of pairing dissimilar cases together and trying to find similarities as well as pairing similar cases together and trying to find differences. This method of analysing data can yield insight into otherwise overlooked between-group patterns as well as counteracting biases.

\section{Similar pairings}

Medimage and Cybersoft both rate high on the complexity of their science challenge and low on the complexity of their market challenge. Both companies are developing new software products which are spin offs of world-leading academic research. In terms of business maturity, the companies are very dissimilar: Cybersoft is a large and wellestablished company with a whole range of products, while Medimage is a market newcomer, a SME and has one product. However, both have large customers and market pull for their new products. Their customers require very high levels of quality and reliability of product. The process of product development is prescribed by the customer to an extent for Cybersoft and to a high degree for Medimage. Both companies use a formal and specification-driven software development process which will be discussed in greater detail later on.

Digitaldeal and Financialware both score low for science and high for product.

Science plays a role for each company mainly in terms of understanding online behaviour and 
optimising design principles accordingly. Constant extension, optimisation and modification of the main product is the focus for much of the ongoing product development work. Both also are creating spin off new products.

\section{Dissimilar pairings}

Cloudway and Cybersoft are compared as the most dissimilar pair in the sample according to the complexity rating on the CIM. Cybersoft scores high on science, Cloudway low; Cybersoft scores medium on product and low on market, while Cloudway scores high on both. While both companies are working intensively on their new product development, it is the challenge from the market pole which was most revealing in the interviews. The Cloudway data demonstrates a huge focus on the complex challenge of creating, proving and keeping up with an intense, international and fast paced market. The more niche market in which Cybersoft is operating with its new law enforcement product offers a different level of complexity. Both companies have relatively new products, so have a focus on brand new product development currently. The differences in the way the NPD takes place at each of these companies will be discussed in the next section.

\section{In depth examination of the data}

After the previous coding, sorting and comparing exercises, it was time to analyse the data in depth for participants' own descriptions of their NPD.

\section{The customer in NPD}

Working with customer requirements is a major topic in software development, and the data is no exception to this. One participant described the challenge as being one of mutual discovery:

[The customers] don't have the luxury of sitting down and thinking for months and writing the perfect specifications. And then handing that over to the software development company here or offshore and waiting another year for the product to be developed. Innovation companies do not have that luxury as the whole idea is that they are actually discovering what the product needs to do as they go along (Bizware).

Information stickiness is a term which describes how hard and expensive it can be to get the tacit knowledge needed for the product build from the potential customers. Sometimes this has to do with the phenomenon of "I will know it when I see it" (Smith, 2007, p. 4). This 
can be frustrating for innovating companies. One participant recounted how during a prototyping phase it was difficult to keep his community beta testers engaged. However, "when you ask them if they see value [in the product] they say "oh, definitely" (Infotree). The product was clearly not at the point where it was meeting market needs. Beta testers (as potential future paying customers) were dropping out. While there seemed to be value in the product concept there was uncertainty in how the product needed to be developed further. This feedback into the new product build can come from many places. The same participant illustrated how they tried to measure customer engagement with the product. The company had many users on their platform using a limited product version; the problem was in converting these users into paying subscribers. He described this engagement measure as one which would help them understand the "Difference between sign up and buying" (Infotree). This gap in measurements is also the gap which would help Infotree better tailor the product offering to its market. It is the sticky information or tacit knowledge which is hard to obtain for some kinds of new products. The Infotree participant went on to clarify that this has a lot to do with education, or changing the customer's current behaviour, rather than the features themselves. "We knew what features we had to do, but when we started to get lot of those features in we found that we were still hitting barriers around adoption. I think there is definitely an element of education in the market. There are a lot of people who don't know that they need something like [the product]" (Infotree). The information needed for the product build is sticky.

Another participant saw uncertainty reduction in building from customer requirements as an exercise in reducing the 'delta'.

We want to keep the loop as tight as possible so [developers] deal with customers directly. As the relationship moves then customers deal much more with customer service teams. When we are doing implementation with the customers we try to have customers and developers talking as much as possible. As the delta in the customer requirements because much less, ideally zero, they deal with customer service (Webfabrik).

Negotiating priorities with the customer is necessary for all companies but especially so when the company is still developing the product. Webfabrik illustrated this negotiation with the customer: 
Well, we say, we have this product pipeline and of the ten things which get you to $100 \%$ we are already doing three and five, and you have one, two and four and so in order to get you to $100 \%$ we need to bump those other things up the priority or resource up that requirement. So that's how customers have a big say. Because we are actively pursuing large customers and we know that we can't meet their needs instantaneously (Webfabrik).

Participants often view product customisation in terms of responsiveness to their markets. Either it was a changing requirement directly from the customer or a new opportunity arising. This participant enumerates multiple product iterations leading to a new market "Needed to keep refining it, getting it out there. Refining again. So started to shift our model, rather than to enterprises [...] and then we can move into a more [individual] access model" (Infotree).

Another participant, whose product is more mature, related how they always solicit feedback from the customer in a very guided and limited fashion. "We don't want to get into too many design debates with our customers. We say to them 'here is how we are going to do it. Are there any obvious inefficiencies to this?' ... We only present things we have thought about a lot. It's hard enough to get to consensus internally." He adds "you can go out to too many users" (Financialware). Sometimes improving your tacit knowledge around product design cannot be improved by spreading a wider net.

Customers sometimes think just one more feature or iteration will solve the problem. This scope creep can be expensive. One participant describes this "We do the work. Have the project. Then the software vendor says, 'no-one is going to buy it unless it has this feature'. So we do some work. 'Ahh actually, the first customer has tried it and we need this feature.' Continuing to add features and not getting revenue... It has been really frustrating" (Cloudway).

\section{Workflow management in NPD}

Working in iterations was one of the key themes in all the interviews. Regardless of whether the participants said they were working to a waterfall, agile or stage gated model, all discussed running through several product iterations. Two participants stood out as working to a different software development method. Medimage and Cybersoft, as previously discussed in the pairing exercise, are both currently developing science-driven new products with strong market pull. They both deploy their own variations of a stage gated method. In 
both cases they deploy degrees of iterations from agile and lean software development methods. However, what is significant in comparison to very iterative NPD is that there are comprehensive upfront specifications and timelines guiding the development work thereafter. These phases were also stage gated. Their customers are healthcare organisations and law enforcement agencies. For Medimage, one of the key constraints is market regulating bodies and required ISO standards. Working with the customer, and their quality demands, is less about creating products which can be discovered together, rather it is more about executing specific technical requirements to a high quality. Unlike the other participants Medimage stressed that there would be a very detailed design and requirements documents signed off by the customer before the build began.

In contrast, Financialware had a quite different workflow process in place. They do not have a long analysis phase in order to produce a comprehensive requirements document. Instead, the business analyst, who knows the product well, works with a designer directly to produce a mock-up of the proposed product. Much effort is made to create a mock-up which looks and feels like the final product. Financialware described itself as a design-led company and so proving the UI and interaction design is a focus. The outcome of this process is a set of lightweight specifications which are improved upon as the build starts. In this way, specifications evolve over time, rather than fixing them early. "They will work on the spec [document] almost retrospectively so as they cycle around this idea of analyse, design, build, analyse, design, build, analyse feedback throughout that loop. You get the feeling of the product evolving". From here on construction of the product and testing is tightly integrated while the functionality of the product grows. Only at the end and before the product release does "pure" testing in a pre-live environment take place with lock downs.

In contrast Digitaldeal described their workflow as "We err on the release often and fail fast approach rather than taking three months to go through that massive development process signed off and then big release. [We] can always draw something back". (Digitaldeal) For this company, failing fast is a feasible approach. The risk to the customer base can be managed by making the failure impact small and reversible. The participant mentioned tactics such as limiting the user group which would see a new feature, timing the release to low traffic hours and reserving the option of rolling back fast. Other participants do not have this luxury since failure would have an unacceptable impact with potential for litigation, financial loss, and reputation damage. The need for accuracy and reliability of the systems which Medimage provide in the health care sector means that prototype testing in a live 
environment is not feasible. This creates a challenge for the company as their product must be correctly interlinked with existing systems with no chance of failure. It was the experience of a major failure which led to process improvement around this kind of risk:

We had one problem at a site. We thought we had fixed it but it generated another issue which we didn't foresee when we did the fix. But now when we do those fixes the whole company comes in and does a review of it to try and see if there are any implications of doing that fix (Medimage).

In an agile or iterative environment, measuring progress can be a source of tension. Measures which were used in the past such as hitting deadlines against the requirements document or counting lines of code are not so relevant. Digitaldeal describes responding to a request for timelines: "You can have whatever is ready on that date, but I don't know what that will be". Progress is measured however:

For a project we will break it down into user stories, agile kind of approach, random point system which is consistent and work out our total count of points for the project and evaluate our philosophy as we burn through those points with each iteration. Assuming those points are accurate with iteration then we can see when we are likely to release. We can say, "well it might be six or seven sprints' worth and get it to you roughly by the end of August". Then we continually expose the stakeholder to what we are doing "here is sprint one and a demo, here is sprint two". Plus we have our burn charts for progress so it is never a surprise where we are tracking (Digitaldeal).

In contrast at Cloudway, where they use an iterative agile NPD process, timelines are worked into their Product Roadmap and there is an expectation that the development team will track progress against that. In addition, the progress and number of patent applications are measured.

How to prioritize development work is an important topic for all participants. For some this task was more complex than for others. This depended mainly on the product and market maturity as well as customer dynamics and company cashflows. For all participants, the number of important tasks demanding attention was always greater than the amount of resource available at any one time.

One participant, a product development manager, describes his whole role in terms of managing the opportunity/priority conflict (Financialware). Financialware is a company in growth mode with an established product. Development work on the product increases the 
competitiveness and market reach of an already successful product. Regarding efficiency and effectiveness, this participant illustrated how work teams are matched to priorities, and the "differences in opinion" over how this could best be achieved:

Higher management thinks that [having] more specialised teams is a way to make us go faster. Build a team around that need. I think that a better way is that we are already working around things which have the highest need. As people mobilise around things which have the highest need you will see a natural evolution of these groups of people who stay on this feature or product (Financialware).

Similarly the best way to ensure efficiency and effectiveness of the developers is a focus at Digitaldeal, which is also a company with an established product. The head of development describes the pain of "context switching" when work is not properly prioritised.

Even if it's just a half-an-hour question and then half-a-day research, it is actually going to be a lot more time invested in that because of the time wasted switching tasks. So we have established a project gateway process whereby we effectively check that it is the right thing to do against our strategy, resourcing and that happens as early in the process as possible (Digitaldeal).

Infotree, whose product is still very new and is grappling with difficult market uptake, prioritizes all development work against one key objective: making things easy for the customer: "All of our development work has been prioritised against that objective. Anything which sits outside of that doesn't get any look in unless it is a major customer requirement" (Infotree).

Flexibility around development priorities was necessary for one company as they ensured cashflow:

I think the problem is that a lot of the projects we have undertaken the agenda has been driven by who is paying for it. The client. It has been frustrating for us as we have deviated from our core principles and core strategy [of] building IP purely because we needed the money. Our development path has been influenced by who has been paying for it (Cloudway).

Continuously improving product development processes and being effective is an issue for all participants. Cloudway and Webfabrik described the difficulty of striking a balance between controlling and measuring what is going on during NPD while avoiding 
becoming weighed down with bureaucracy and destroying a flexible working environment. A planned product development process is desired without losing a special culture of openness and flat hierarchy.

For Medimage, prioritisation of development work as a pressure is not so evident in the data. Possibly this is because of the intense focus on solving the science-side problems. Also it is possible that the strict phased approach of the development alongside a very clearly defined software product reduces the challenge and complexity of software development prioritisation. For instance, the Medimage participant describes the iterative waterfall style development approach:

There is a strict phased approach to it. Five phases. So that will go into what we call the suggestion phase. We see if it makes sense. Then it goes into inception to see if there is a physical business case, then we go into elaboration where we end up signing off with the customer what we are going to build (Medimage).

Prioritisation also means creating a sustainable pace of work. One participant reflects on this, saying it can be the emotional strain of incoming customer requests or technical issues which forces the pace of work into overdrive:

I learnt recently to create a gap between the issues you are looking at and yourself so that your ability to look at the issues objectively is better. Otherwise when an email comes in you instantly think "right I have to fix that issue!!" and that's what I am working on until I have fixed that problem. As a risk management process it is not terribly smart as you are always burning the candle at both ends, you are reacting emotionally in an intellectual pursuit like software development which is a bad thing. You make mistakes, you skip over things, you think “f**k I will fix this later!” and you never do. Five years later it is still a bug (Webfabrik).

\section{Development teams in NPD}

The usual development team size described by participants was four to seven people. These teams are either led by a product manager, a lead developer or operate as a selfmanaging team. Developers usually work with a large degree of autonomy and are expected to work towards set goals without much supervision. There are varying degrees of authority to make changes depending on the implied hierarchy of the organisation. Balancing this 
autonomy is a constant flow of communication and feedback described by all participants. Examples were given of daily stand-up meetings, internal forums, water cooler chats and accessible office spaces.

Basically we are operating with a reasonably tight knit and small developer team on this project, depending on the area they are working on some of them have daily stand up meetings. Use techniques like boards to keep track of what needs to be done use GoogleDocs for documentation, shared amongst the team (Cybersoft).

While some companies have developers in different cities or even different countries most resisted splitting their core development teams up. When there was a splitting of the team, the effects of losing co-location were minimised. For instance, the Cybersoft participant describes how " $80 \%$ of the application development is done in Christchurch. Satellite in Dunedin and Melbourne. Wouldn't want to spread our wings too much. Advantages to having your resources closer together as interact much more closely. Easier to network with your peers" (Cybersoft). Another participant extends this idea: "[Colocation] works really well when you have satellite teams which are autonomous [and you are not] breaking up [the] core product team" (Financialware). Working in the same physical space brings benefits which are so important that it warrants flying in a remote team member on a regular basis: "One person [from the development team] lives in Auckland but spends one week per month with the team in Wellington. Here so that he can be part of the culture and the team and see what has happened" (Cloudway). Marketing, sales, science functions or even the CIO could be working remotely according to the participants.

Participants were varying in their responses to the challenge of finding the right talent for their NPD. One said that it had been a major problem. Since Webfabrik's technology was the first in the local market, there were not existing experts in the area. In contrast another participant said that being based in Wellington was an advantage as he could leverage off the existing talent pool from the established film industry and experts in imaging technology. On the other hand, his search for the right science experts was international. Cybersoft recruits expert resource from its local university which has specialisations in mathematics and statistics.

The culture of work was also referenced by many participants and included notions such as staff morale, looking good in the eyes of your team mates, open communication, trust and supporting developer-led initiatives. Transparency regarding what is happening internally 
as well as externally was very important at Cloudway. The participant noted that he updates "with everyone once a month to see what is happening. Everyone can speak, no bad ideas. ....[in our] open plan office we talk about everything. I have always believed that nothing should be hidden" (Cloudway).

\section{Managing the build in NPD}

Giving developers the time to work on projects of their own choice was referenced by two companies in the sample. These experimentation days, such as are well established at Google, were put in place with the intention of boosting creativity and keeping developers interested. "Every second week you have half a day where you can just down tools and work on anything you like. Completely unrelated to [Financialware] if you want. But actually what happened is that almost everyone did something related to [Financialware] building something which they thought was cool on Financialware" [Financialware].

Prototyping plays an important role for NPD in all companies. The understanding of what a prototype is differs across the data; some participants described it as a beta version of the final product, while others saw it as a proof of concept that would be mostly discarded. However, valuable learning and experimentation were key aspects of both understandings. For instance, the participants described ways of experimenting with new product features or spin off products, as well as frontloading the risk of developing more fully workable products by creating first a partial build. Webfabrik described a product prototype which was opened up to the customer base but was not very successful - it had quality and communication issues. The participant reflected that next time he would do it very cheaply to start off with and only put resources in when it showed success.

You make this decision before you go into it. You say "right we are going to give this 90 days and after that 90-day period I am going to match it up with what I thought success looked like" if there is no match then we look at what the delta is and say "does this look like success or failure? And if it looks like failure you have to kill, you have to be pretty mercenary about this (Webfabrik).

An intensive variation on this theme was described by one participant as running a mini-competition to give developers a chance to "prove" if their preferred solution to a particular problem was the best: 
So in a recent project we had the opportunity to use a whole bunch of third party libraries to achieve what we were doing. So we said "you work on this, you this, you this" and see after three days who has the best implementation. Mini competition between the developers working on that. After three days we sat down and worked out which one we wanted to go with. The one we ended up going with was not the one we would have chosen had we had to make the choice at the outset. So those kinds of things are really useful to be doing upfront. Obviously you want to make those kinds of decisions early so that you don't have to make that when you are just about to release. Weight our project plans towards those kinds of things early on (Digitaldeal).

Cloudway describes how the product build priorities changed over time as the company matured. "At the start, 'just build something so we can demonstrate that it works'. Then it was 'we better build something more robust'. Then an evolution to 'what does the customer need?' let's get something to market faster and start generating revenue." (Cloudway) Similarly, early in its product incubation, Infotree needed a prototype (beta version) to demonstrate to customers. The purpose of this was to provide a "minimum value point" and also to "get people's attention" (Infotree). In contrast, Medimage describes how prototyping at the customer site does not work for them - the customers will not use a prototype as "the work gets so separate from the workplace that people just don't use it" (Medimage).

One common theme was the reduction of risk in the development cycle. This was often achieved by short iterations which would force issue to surface quickly or stage-gate controls which ensure formal approval in regular intervals. Both approaches have fixed dates for review in common and that the risk mitigation happens by reducing the overall complexity of the task at hand. As one participant put it: "You get to the inception phase and you get to a problem and you say let's not push on too far with the engineering. Let's have the scientists spend two to three months seeing if there is a solution there" (Medimage). Another participant sees risk as a process which can be mitigated: "And so really what risk becomes is an identification of potholes down the road. Steer between the potholes or find the straightest line" (Webfabrik).

A further kind of risk is not understanding the customer or wasting developing time on product features which are not useful. Financialware described how their approach was to be careful at decision points. When asked "what most represents risk for you in the 
development process?" The Financialware participant replied "Risk is that we don't represent the needs of our users". Another participant discussed this issue further:

Nothing we added or enhanced in the product was of little value or no value to any of their customers. It was interesting because this company was not technology innovators but they were business innovators and this is a very critical success factor to any innovation business. They think of their product from the perspective of their customers, not their internal conversation of what they think the product should have (Bizware).

\section{Innovation management from the founder perspective.}

Four of the eight participants were company founders. They brought an additional perspective to innovation complexity: that of overall governance of the company while developing new products. Their role of working on the business as well as in the business was clear in the data.

One theme for the founders was working from New Zealand. The Cloudway founder discusses the difficulty this has posed for his NPD in terms of market access. "The trouble is that business is about relationships. You can meet in person, have a coffee. But it's more fundamental than that. If you don't live [in the US], we don't know if you are committed to this market. If you are just going to fly in once a quarter and try to sell me something, I don't get a feel. We don't know who your company is. If you are going to be here tomorrow" (Cloudway). To mitigate this risk, the company invested in renting office space in the customer's market and hiring a local US marketing manager. Interestingly, having the core development team working out of New Zealand is not an issue for American customers "they have crossed that [bridge] all in the past with outsourcing" (Cloudway). Trust is not diminished by the software development taking place in New Zealand.

The Medimage founder also saw no issue in working from New Zealand. Science is international and is generated through universities and researchers according to standard academic practices; collaboration is commonplace in this area and not unexpected. The software product Medimage is developing is also highly regulated by the FDA and so the company is shielded from market doubt over quality by the strict certification standards. Access to grants and government support for NPD was described as relatively easy to come 
by for this company. The founder had access to a network of valuable supporters within universities and businesses internationally. To keep up with the science, constant environment scanning was important and this involved travel to international conferences and networking with researchers overseas: "The whole world is virtual and we live on Skype" (Medimage).

In contrast, Infotree, Webfabrik and Cloudway emphasised that the venture capital market is very challenging in New Zealand and that this is a huge barrier to developing innovative new software products. This barrier forced all three companies into do-it-yourself bootstrapping in the early stages of their NPD. Two founders developed the initial software product themselves and the third relied on self-financing a developer so that the product could be brought to first customers. Cashflow concerns for these three companies have directly impacted on how their NPD is executed.

The strain of managing a growing business with a multitude of pressures, such as cashflow and venture capital, was evident in the founder data. For Bizware founder, governance is where innovation succeeds or fails:

Often a new innovation has no company behind it yet, just a start up so governance is very important. [The ] very simple reason is that innovators are a particular type of people who are good at innovating but not anything else. Big mistake that happens in NZ is that innovators - because they have been able to successfully innovate an idea [and] solve a problem - they believe that they can do everything else around it too. And some of them can, they go and learn. But at the price of taking so much longer to get to the market and get successful. There is a difference between a hobby innovator and a business innovator: revenue! (Bizware)

Governance and the strain of managing so many complex tasks when cashflow is still uncertain is clear in the Cloudway founder's description:

$[\mathrm{T}]$ he thing which breeds innovation is often the ... single-mindedness and you have to be desperate. And from that comes a bit of chaos. Within the company the people felt it was too chaotic. Now we have become more open and more diligent. And what causes a lot of the chaos is that you are scrambling. And you are trying to make payroll and you are trying to develop a new IP and that is being driven through an external party through funding. If you are the developer sitting here saying "but you told me we were doing that?!" People are pretty quick to put their hands up and say "Where is this 
coming from" Why are we doing this?" So it doesn't need to be as chaotic if you are hugely well funded. Well that is great if you have $\$ 5 \mathrm{M}$ (Cloudway).

This tone, of personal exertion, pressure and its impact on NPD, was echoed in the Webfabrik and Infotree data. Not only do capital constraints play a role, but also time. To be a forerunner, time to market can be crucial. Infotree described how having to proceed more slowly with the NPD has been a side effect of resource constraints and in the meantime the market has changed with competition springing up.

\section{Discussion}

The purpose of this study has been to examine how the development of software products is managed in the New Zealand context.

Two questions have guided this research:

- What approaches to new product development do companies take when creating software products?

- How does complexity relate to the new product development approach?

The first point which became very clear during the data analysis is that there is a lot of variation in the management of NPD. Four broad themes emerged from the data: the customer, workflow management, development teams and managing the build. All participants except one described adjusting their software development methods to the particular challenges of the emerging product. The one company which was required to be dogmatic about their software development method was Medimage; the method used is a condition of the customer's regulating agency.

There were many re-occurring themes in terms of innovation complexity. During data analysis, reoccurring constructs were coded according to the categories of innovation complexity (as per the CIM poles market, technology, product, science); working on the business; company description and participant role. The innovation challenge was given a measure in terms of complexity. Complexity has a technical meaning here derived from Jaques: it describes the difficulty of a task in terms of length of time and number of decisions it takes to complete (Brown, 2011). The data were coded in terms of where it fit on the CIM 
and rated according to estimated complexity of each. The link between companies which had similar kinds of innovation complexity and their NPD strategies became clear.

Companies whose innovation complexity was high were more likely to favour an iterative NPD method. They did not create upfront specifications; rather they allowed the details of the NPD to emerge during many iterations. They variously involved the customers and were careful to do this appropriately. It is possible to see many variations on iterative software development methods in the data. The common practices included: being able to chunk the project into manageable complexity, using prototyping, partial builds, upfront design dummies, experimentation and learning from small and early failures (where appropriate). It is clear that agile was the preferred software development method for its ability to embrace changes.

Two participants, Medimage and Cybersoft favoured a more stage gated software development method. This was appropriate to their innovation complexity and they were able to additionally focus on process efficiency. For both participants, it was very clear what their new products needed to do, and the challenge was in ensuring that the software would do this reliably. The complexity of the innovation challenge lay in the science and knowledge of this area is critical to their success. One drawback to this more formally process driven model is that fast prototyping or development is not possible.

A dimension which is revealing across the data is company maturity. Digitaldeal, Financialware and Cybersoft are all established companies with large workforces. They all have customers from different sectors and at least one established product. The participants all described well established workflows and emphasised that efficiency of development was important. Two companies also spoke explicitly about maintaining the balance between efficiency and creativity. At Digitaldeal and Financialware, the elements of this are company culture (openness, flat hierarchy, self-managing teams) and techniques for exploring new ideas (e.g. experimentation days). When recruiting new team members at Digitaldeal, if a candidate for a role was technically brilliant but there were doubts over team fit, then this candidate would not be considered for the role. Alignment with culture and fit are considered overwhelmingly important. At Cybersoft (and Medimage) the scientific expertise is emphasised in the interview data, and the participants explained that this expertise is necessary to solve their innovation complexity. 
Sorting across this dimension for the startups (Webfabrik, Infotree, Cloudway, Medimage) is also revealing. All interviewees from this group are company founders. Once again, Medimage's data stand apart from the rest of the participants across this dimension. Webfabrik, Infotree and Cloudway all describe chasing an emerging market and the strain of doing so. Their NPD focus is on flexibility, adapting to circumstances, environment scanning, building relationships (and the challenges of doing so - intergenerational, cultural, and across borders variously). Words such as "emerging", "adapting", changing" and "evolution" occurred often in their data. Managing their teams, the feeling of responsibility for staff during uncertainty and maintaining motivation was explicitly a focus in Cloudway and Webfabrik's data. Being nimble about able to change direction, often if necessary is part of the innovation challenge for these participants. All three experience complexity on many poles of the CIM (market and product in particular). Medimage's data do not give a sense of personal strain on the founder or the need to constantly shift priorities. Both the market and the product are very clear for this company. The founder also described the good fortune of having very strong personal connections to influential people in his area. The focus of the NPD is on excellent, reliable quality, process driven development and constantly scanning the science for developments. Complexity for this participant lies in providing science solutions for problems and the delivery of the new product is about an achievable - if difficult execution.

The Bizware data also stand out in some ways. Bizware is a company in growth mode, and provides many new software products to business customers. Governance is stressed by the participant as key to success in NPD with software products (which is described in similar terms to the entrepreneurship concept in the CIM). Working for the customer's customer is the measure of success in any project and complexity in innovation lies in building a product which creates value for the customer's business. Hence, NPD is a process of mutual discovery and highly iterative, flexible new product development is favoured alongside developing close, consultative, trusting relationships. Each NPD is a puzzle to be solved creatively, keeping constraints such as value and cashflow in mind.

Finally, the founder data gives insights into working from NZ, the local innovation ecosystem, and the personal strain of managing innovation. Entrepreneurial skills are very much in evidence in this data as almost all had high innovation complexity. Balancing the various needs of the new product against so many factors is a constant effort. 


\section{Conclusion and Future Research}

Earlier, Drucker (1985) was quoted at length discussing innovative entrepreneurship. He mentions that entrepreneurship is capable of being learned and practised and the key is understanding the principles. This study has observed that while there are many approaches to NPD which NZ tech companies take, the level of innovation complexity is a determining factor of the kind of approach. Complexity is inherent in innovation whether it is the market, the technology, the product, or the science. It requires a long term view as well as short term nimbleness. Many skills are needed to manage the demands of NPD; the many decisions which need to be made, the flexibility to adapt to changing circumstances, to balance workflow efficiency with creativity and to manage the personal strain when you are a startup founder. This study suggests that this is one of the key principles of innovating with software products: recognizing and responding to innovation complexity with appropriate new product development strategies.

In reality this seems to be saying something quite simple. Successful companies match the way they do business to the challenges they face. What is remarkable in this respect is that when companies are more under pressure - characterised here by higher levels of innovation complexity - it is the strength of the entrepreneurship which comes to the fore: making sometimes risky decisions, ensuring flexibility, focusing on the right priorities, scanning the environment for changes and opportunities all while motivating the team. This can feel chaotic and it is hugely challenging when there is high complexity involved.

Further research in this area could develop a contingency model linking innovation complexity to NPD approach. In addition, this study has been limited by the amount of data gathered from each participant. Further research might gather a cross-section of data from a variety of sources in order to offer greater insight into the different roles, (founder, product manager), the complexity of the new product and the dimension of business maturity.

Given that innovation is more complex in a networked world, where customers have high expectations of individualised products, wrap around services and experiences, companies will need to continue to adapt and understand their innovation practices in order to compete successfully. 


\section{References}

Annacchino, M. A. (2003). New Product Development : From Initial Idea to Product Management. Oxford: Butterworth-Heinemann.

Barczak, G., Sultan, F., \& Hultink, E. J. (2007). Determinants of IT Usage and New Product Performance. Journal of Product Innovation Management, 24(6), 600-613. doi:10.1111/j.1540-5885.2007.00274.x

Benediktsson, O., Dalcher, D., Reed, K., \& Woodman, M. (2003). COCOMO-Based Effort Estimation for Iterative and Incremental Software Development. Software Quality Journal, 11(4), 265-281.

Berkhout, A. J., Hartmann, D., \& Trott, P. (2011). The role of entrepreneurship in innovation. International Journal of Entrepreneurship and Innovation Management, 14(1), 6079. doi:10.1504/IJEIM.2011.040822

Berkhout, G., Hartmann, D., \& Trott, P. (2010). Connecting technological capabilities with market needs using a cyclic innovation model. $R \& D$ Management, 40(5), 474-490. doi:10.1111/j.1467-9310.2010.00618.x

Boehm, B. (2011). Architecting: How Much and When? In A. Oram \& G. Wilson (Eds.), Making Software: What Really Works, and Why We Believe It (pp. 161-186). Sebastopol, CA: O’Reilly.

Brown, J. (2011). The legacy of Elliott Jaques. International Journal of Applied Psychoanalytic Studies, 8(1), 89-94. doi:10.1002/aps.273

Callaghan, P. T. (2009). Wool to Weta : Transforming New Zealand's Culture and Economy. Auckland, N.Z.: Auckland University Press. 
Cooper, R. G. (2008). Perspective: The Stage-Gate Idea-to-Launch Process-Update, What's New, and NexGen Systems. Journal of Product Innovation Management, 25(3), 213 232. doi:10.1111/j.1540-5885.2008.00296.x

Curzio, A. Q., \& Fortis, M. (Eds.). (2005). Research and technological innovation the challenge for a new Europe. Heidelberg; New York: Physica-Verlag.

Derby, M. (2012, February 29). Inventions, patents and trademarks - The "no. 8 wire" tradition. Te Ara - the Encyclopedia of New Zealand. Retrieved March 28, 2012, from http://www.teara.govt.nz/en/inventions-patents-and-trademarks/1

Dodgson, M., Gann, D., \& Salter, A. (2008). The Management of Technological innovation : strategy and praxis. Oxford, UK: Oxford University Press.

Drucker, P. F. (1985). Innovation and entrepreneurship : practice and principles. London: Heinemann.

Drucker, P. F. (2002). The Discipline of Innovation. Harvard Business Review, 80(8), 95103.

Eisenhardt, K. M. (1989). Building Theories from Case Study Research. The Academy of Management Review, 14(4), 532-550. doi:10.2307/258557

Fletcher, H. (2012, October 2). Wheedle site shut down indefinitely. New Zealand Herald. Retrieved from http://www.nzherald.co.nz/business/news/article.cfm?c_id=3\&objectid=10837782 Hagedoorn, J. (1996). Innovation and Entrepreneurship: Schumpeter Revisited. Industrial and Corporate Change, 5(3), 883-896. doi:10.1093/icc/5.3.883

INSEAD. (2012). The Global Innovation Index 2012. Fontainebleau. Retrieved from http://www.globalinnovationindex.org/gii/main/fullreport/index.html

Larman, C. (2004). Agile and Iterative Development : A Manager's Guide. Boston: AddisonWesley. 
Larson, A. L. (2000). Sustainable innovation through an entrepreneurship lens. Business Strategy \& the Environment (John Wiley \& Sons, Inc), 9(5), 304-317.

Loch, C. H., \& Kavadias, S. (2007). Handbook of New Product Development Management. Amsterdam; New York: Butterworth-Heinemann.

McConnell, S. (2004). Code Complete: A Practical Handbook of Software Construction (2nd ed.). Redmond Wash.: Microsoft Press.

McConnell, S. (2011). What Does 10x Mean? Measuring Variations in Programmer Productivity. In A. Oram \& G. Wilson (Eds.), Making Software: What Really Works, and Why We Believe It (pp. 567-574). Sebastopol, CA: O'Reilly.

Meeus, M. T. H. (2006). From R\&D Management to Management of Innovation. Research on the Organizational Factor, Trends, Mainstream and Hidden Treasures. In J. Sundbo, A. Gallina, G. Serin, \& J. Davis (Eds.), Contemporary Management of Innovation: Are We Asking the Right Questions? (pp. 21-38). New York, N.Y.: Palgrave Macmillan.

Ministry of Science + Innovation. (2011, December 1). Statement of Intent 2011-14. New Zealand Government, MSI. Retrieved from http://www.msi.govt.nz/aboutus/corporate-publications/statement-of-intent/

Nonaka, I., \& Kenney, M. (1991). Towards a new theory of innovation management: A case study comparing Canon, Inc. and Apple Computer, Inc. Journal of Engineering and Technology Management, 8(1), 67-83. doi:10.1016/0923-4748(91)90005-C

O’Reilly, C., \& Tushman, M. (2007). Ambidexterity as a Dynamic Capability: Resolving the Innovator's Dilemma (Research Paper). Stanford University, Graduate School of Business. Retrieved from http://econpapers.repec.org/paper/eclstabus/1963.htm 
Pikkarainen, M., Codenie, W., Boucart, N., \& Heredia Alvaro, J. A. (2011). The art of software innovation eight practice areas to inspire your business. Berlin; Heidelberg: Springer.

Punch, K. (2005). Introduction to Social Research: Quantitative and Qualitative Approaches (2nd ed.). London; Thousand Oaks Calif.: SAGE.

Sandberg, B. (2008). Managing and Marketing Radical Innovations: Marketing new technology. Routledge Studies in Innovation, Organization and Technology. London; New York: Routledge.

Shanahan, G. (2011). TIN100 Industry Analysis: New Zealand 2011 (7th ed.). TIN100 Industry Analysis. Auckland, N.Z.: Technology Investment Network Ltd.

Smith, P. G. (2007). Flexible product development : Building agility for changing markets. Hoboken: John Wiley.

Stevenson, H. H., \& Jarillo, C. (1990). A Paradigm of Entrepreneurship: Entrepreneurial Management. Strategic Management Journal (1986-1998), 11(5), 17.

Sundbo, J., Gallina, A., Serin, G., \& Davis, J. (Eds.). (2006). Contemporary Management of Innovation: Are We Asking the Right Questions? New York, N.Y.: Palgrave Macmillan.

Trott, P. (2012). Innovation Management and New Product Development (5th ed.). Harlow, England: Prentice Hall/Financial Times.

Ven, A. H. V. de, Polley, D. E., Garud, R., \& Venkataraman, S. (1999). The Innovation Journey. New York, N.Y.: Oxford University Press. 


\section{Appendix A - Interview Schedule}

Theme 1: Flexibility

- How do you deal with changes to your new product while it is under development?

- What is the role of product iterations?

- How is flexibility built into the NPD process?

Theme 2: Prototyping

- Do you use prototyping or experimentation?

- How do you measure progress?

- Which metrics matter?

- How do you collect and share knowledge (on lessons learned from the prototype)?

Theme 3: Uncertainty and risk

- What kinds of uncertainty do you have during NPD?

- How does this feed into your planning?

- What is the most crucial success factor for you?

- Do your customers know what they want or need from the new product?

Theme 4: People management

- How has your approach to the organisation of work changed over time?

- What is the ideal team composition?

- What drives innovative behaviour?

- Where do you find the talent needed for your NPD?

Theme 5: Collaboration

- How do you collaborate?

- What role do customers play in your NPD?

Theme 6: Innovation Ecosystem in New Zealand

- How important is it to be the "first mover" in NPD?

- What are important factors in the innovation ecosystem?

- What role does Free Open Source Software (F/OSS) play in your NPD process? 


\section{Appendix B - Interview Invitation}

Re: Victoria University of Wellington research into software innovation

Dear (participant's name),

As part of my Master's research into innovation and software development, I am inviting a number of NZ-based, hi-tech companies to participate in a short interview. This will be an informal conversation where I will ask for your views on the process of new product development. The research aims to answer the question "which factors influence development of software products in the NZ context?"

Participation will involve about one hour of your time. In order to safeguard your confidentiality, identities will be disguised. I will make myself available to you at your convenience, either by phone or in person.

Ideally the interview participant is a senior manager who has been close to the product development process.

It would be fantastic if (company name) were able to be included in this research.

Kind regards,

Holger Spill 